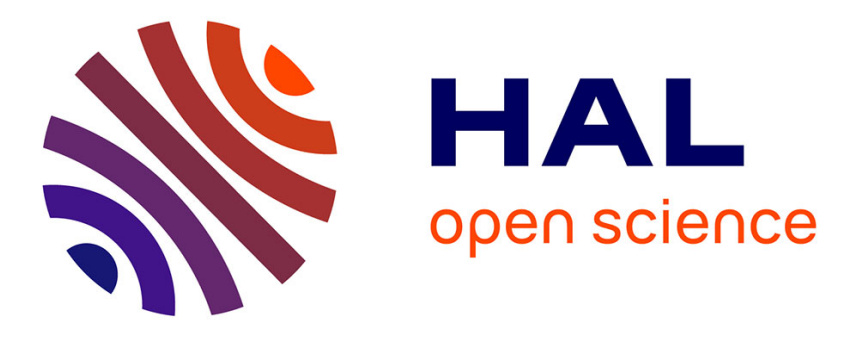

\title{
Circularly Polarized Fluorescent Helicene-Boranils: Synthesis, Photophysical and Chiroptical Properties
}

Aurélie Macé, Khaoula Hamrouni, Etienne S Gauthier, Marion Jean, Nicolas

Vanthuyne, Lucas Frédéric, Grégory Pieters, Elsa Caytan, Thierry Roisnel, Faouzi Aloui, et al.

\section{To cite this version:}

Aurélie Macé, Khaoula Hamrouni, Etienne S Gauthier, Marion Jean, Nicolas Vanthuyne, et al.. Circularly Polarized Fluorescent Helicene-Boranils: Synthesis, Photophysical and Chiroptical Properties. Chemistry - A European Journal, 2021, 27 (29), pp.7959-7967. 10.1002/chem.202100356 . hal03194340

\section{HAL Id: hal-03194340 \\ https://hal.science/hal-03194340}

Submitted on 23 Apr 2021

HAL is a multi-disciplinary open access archive for the deposit and dissemination of scientific research documents, whether they are published or not. The documents may come from teaching and research institutions in France or abroad, or from public or private research centers.
L'archive ouverte pluridisciplinaire HAL, est destinée au dépôt et à la diffusion de documents scientifiques de niveau recherche, publiés ou non, émanant des établissements d'enseignement et de recherche français ou étrangers, des laboratoires publics ou privés. 


\title{
Circularly Polarized Fluorescent Helicene-Boranils: Synthesis, Photophysical and Chiroptical Properties
}

\author{
Aurélie Macé, ${ }^{[a]}$ Khaoula Hamrouni, ${ }^{[a, b]}$ Etienne S. Gauthier, ${ }^{[a]}$ Marion Jean, ${ }^{[c]}$ Nicolas Vanthuyne, ${ }^{[c]}$ \\ Lucas Frédéric, ${ }^{[\mathrm{d}]}$ Grégory Pieters, ${ }^{[\mathrm{d}]}$ Elsa Caytan, ${ }^{[\mathrm{a}]}$ Thierry Roisnel, ${ }^{[\mathrm{a}]}$ Faouzi Aloui, ${ }^{[b]}$ Monika Srebro- \\ Hooper, ${ }^{*}[\mathrm{e}]$ Bertrand Carboni, ${ }^{[a]}$ Fabienne Berrée, ${ }^{*[a]}$ and Jeanne Crassous ${ }^{*},[\mathrm{a}]$
}

Dedicated to the memory of Professor François Diederich
[a] Dr. A. Macé, Dr. E. S. Gauthier, Dr. E. Caytan, Dr. T. Roisnel, Dr. B. Carboni, Dr. F. Berrée, Dr. J. Crassous Univ Rennes, CNRS, ISCR-UMR 6226,
Université de Rennes 1, Campus de Beaulieu, 35042 Rennes Cedex, France.
E-mails: fabienne.berree@univ-rennes1.fr, jeanne.crassous@univ-rennes1.fr
[b] K. Hamrouni, Dr. F. Aloui
University of Monastir, Faculty of Sciences, Laboratory of Asymmetric Synthesis and Molecular Engineering of Materials for Organic Electronics (LR18ES19), Avenue of Environment 5019 Monastir, Tunisia.
[c] M. Jean, Dr. N. Vanthuyne
Aix Marseille University, CNRS, Centrale Marseille, iSm2, Marseille, France.
[d] Dr. L. Frédéric, Dr. G. Pieters
Université Paris-Saclay, CEA, Département Médicaments et Technologies pour la Santé (DMTS), SCBM, Gif-sur-Yvette, F-91191, France.
[e] Dr. M. Srebro-Hooper
Faculty of Chemistry, Jagiellonian University
Gronostajowa 2, 30-387 Krakow, Poland.

Email: srebro@chemia.uj.edu.pl

Supporting information for this article is given via a link at the end of the document.

\begin{abstract}
Mono- and di-boranil-substituted helicenes were prepared by $\mathrm{BF}_{2}$-borylation of the corresponding anils, readily synthesized by condensation of 2-amino- and 2,15-diamino-helicenes with 4(diethylamino)salicylaldehyde. After enantiomeric resolution using HPLC, their chiroptical properties including circularly polarized fluorescence in solution and in PMMA films were investigated and rationalized with the help of NMR, X-ray and quantum-chemical calculations.
\end{abstract}

\section{Introduction}

Helicenes are chiral, screw-like shaped, polyaromatic hydrocarbons (PAHs) displaying strong chiroptical activity. ${ }^{[1]}$ Recently, a particular focus has been put on their circularly polarized emission $(\mathrm{CPL})^{[2]}$ for future potential applications in cryptography, circularly polarized organic light-emitting diodes (CP-OLEDs) technology, bioimaging or photocatalysis. ${ }^{[3]}$ At the molecular level, chiral organic molecules display CPL activity with luminescence dissymmetry factors $\left(g_{\mathrm{lum}}=2\left(l_{L}-l_{\mathrm{R}}\right) /\left(l_{L}+l_{\mathrm{R}}\right)\right)$ of $10^{-4}$ $10^{-2}$, due to underlying electric dipole-allowed electronic transitions, resulting in not necessarily small $l_{L}-l_{R}$, but quite large $I_{L}+I_{R}$, thus diminishing $g_{\text {lum }}$ values. Despite this, such systems have emerged as valuable candidates for CPL applications thanks to their tunable photophysical properties along with easy processing and integration into optoelectronic devices. ${ }^{[3]}$ In comparison, chiral lanthanide complexes are known to show $g_{\text {lum }}$ values that can reach more than 1 thanks to their $f \rightarrow f$ electronic transitions, formally forbidden by Laporte selection rules, which lead to very small $L_{L+} I_{R} \cdot{ }^{[4]}$ However, emission quantum yields reported for such compounds are usually low.

Among all the CPL active organic small molecules, helicenes have been shown to display rather strong CPL activity with $g_{\text {lum }}$ values as high as $10^{-2} .{ }^{[5]}$ Recently, the possibility to incorporate heteroatoms ( $\mathrm{Si}, \mathrm{S}, \mathrm{B}, \mathrm{N}, \mathrm{P})$ into helicene frameworks using various synthetic strategies has attracted a special attention with the aim of creating / expanding structural diversity and tuning the photophysical properties of such systems. ${ }^{[6]}$ In this regard, incorporating boron atoms into helicenes can be considered as a valuable strategy to generate novel chiral materials with tailored properties. For instance, due to the electron-accepting and Lewis acidic characters of boron, introducing one or several $B$ atoms into a helicenic scaffold generally results in strongly blue-emitting chiral fluorophores, such as in CPL-active azaborahelicenes $\mathbf{H 1}^{\#[7]}$ and $\mathbf{H 2}{ }^{\#[8]}$ (Figure 1). The three- or four-coordinate nature of the boron atom enables to construct, not only monohelicenic, but also multihelicenic units, such as oxabora-bishelicenic system $\mathrm{H}{ }^{\#} .^{\left[{ }^{[9]}\right.} \mathrm{BF}_{2}$ fragments can also be introduced within azahelicene units and yield efficient CPL-active orange or red emitters, such

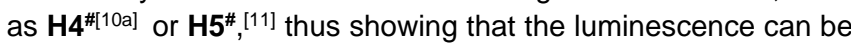
readily tuned by choosing appropriate boron-doped chromophore. The CPL emission can be further modulated by postfunctionalizing the same chiral system with, for instance, a chiral binaphthol substituent on the boron atom in place of the two fluorines. ${ }^{[10 \mathrm{~b}]}$ Finally, instead of incorporating aza- or oxaboracycles into the fused helicenic scaffold, boron-based fragments can be grafted onto a helical core, as shown in the 
configurationally stable pentahelicenic structure $\mathbf{H 6}^{\#}$, which is functionalized with a $\mathrm{BMes}_{2}$ moiety (Mes = mesityl). ${ }^{[12]}$ In this system, the presence of electron-donating $\mathrm{NMe}_{2}$ unit allowed to tune the emission to more red-shifted wavelengths thanks to a strong charge transfer. Furthermore, the vacant $p_{z}$ orbital of boron enabled to use $\mathbf{H}^{*}$ as a fluoride anion sensor with $\mathrm{CPL}$ signal as a read-out response. Note that along with the boron atom, $\mathrm{N}$ or $\mathrm{O}$ atoms are often introduced via B-N or B-O bonds. Indeed, the interaction between the $N / O$ lone pair and the unoccupied $p_{z} B$ orbital enhances the chemical stability of such molecules. Otherwise, sterically hindered substituents, such as mesityls in $\mathbf{H 6}^{\#}$, need to be introduced to protect the boron atom.

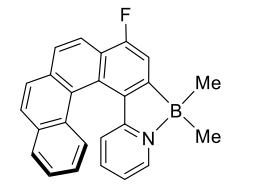

$(P)-\mathrm{H}^{\#}$

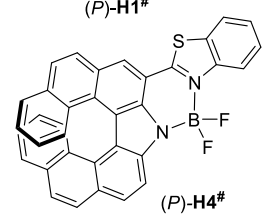

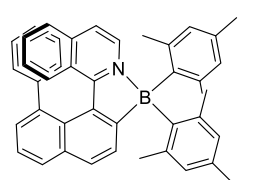

$(P)-\mathbf{H}^{\#}$

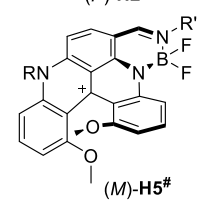

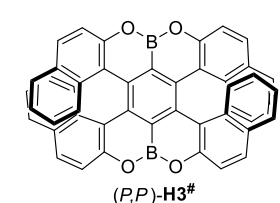

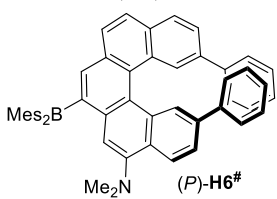

Figure 1. Chemical structures of known boron-based helicene derivatives.

Boranils, another class of boron heterocycles derived from salicylaldanilinimines, possess an $\mathrm{N}-\mathrm{B}-\mathrm{O}$ connectivity and are particularly promising species due to their attractive optical features. ${ }^{[13]}$ Following the pioneering work of Hohaus et al. in $1973,{ }^{[14]}$ Ulrich, Ziessel et al. reported in 2011 the facile two-steps preparation of boranils bearing donor/acceptor substituents, showing higher stability compared to their unsubstituted congeners and good luminescence properties in solution and solid states. ${ }^{[15]}$ In addition, such compounds have the major advantage of being easily synthesized, even in a large-scale, from a variety of anilines or amines, including chiral ones. Although a few chiral boranils ${ }^{[16]}$ or related $\mathrm{BF}_{2}$ compounds ${ }^{[17]}$ with salicylaldehyde-based Schiff-base $N^{\wedge} \mathrm{O}$-containing ligands have been addressed so far, only few of them are CPL-active.

Herein, we report the preparation and detailed characterization of novel boron-containing helicenes $\mathbf{H} \mathbf{1}-\mathbf{H} \mathbf{3}$, which combine carbo[4]- or carbo[6]-helicene moieties and one or two boranil units (Figure 2). In particular, the chiroptical properties of enantiopures $\mathbf{H} \mathbf{2}$ and $\mathbf{H} \mathbf{3}$, together with their nonpolarized and circularly polarized fluorescence, were examined and rationalized with the help of first-principles calculations.

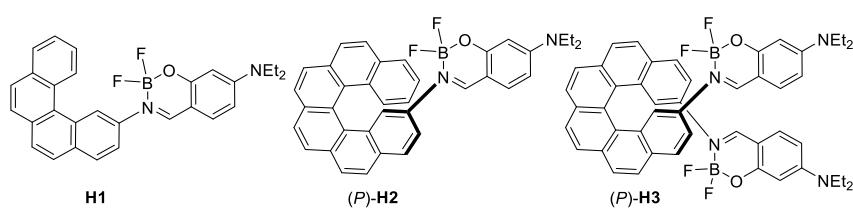

Figure 2. Chemical structures of new helicene-boranils presented in this work.

\section{Results and Discussion}

Synthesis and structural characterization of heliceneboranils $\mathrm{H} 1-\mathrm{H} 3$
Helicene-boranils $\mathbf{H} 1-\mathbf{H} \mathbf{2}$ were first prepared following the general synthetic route depicted in Scheme 1. Namely, heliceneboronate derivatives $\mathbf{1} \mathbf{a}-\mathbf{b}$ were first converted into heliceneamines $\mathbf{2} \mathbf{a}-\mathbf{b},{ }^{[18]}$ which, in turn, gave imines $\mathbf{3} \mathbf{a}-\mathbf{b}$ by treatment with 4-(diethylamino)salicylaldehyde. A final complexation with $\mathrm{Et}_{2} \mathrm{O} \cdot \mathrm{BF}_{3}$ in the presence of $N, N$-diisopropylethylamine (DIEA), in refluxing 1,2-dichloroethane (1,2-DCE) for 21-24 hours yielded the targeted compounds.
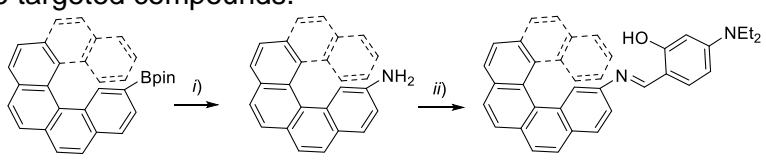

$1 \mathrm{a}$ or $(\mathrm{rac})-\mathbf{1 b}$

$\mathbf{2 a}$ or $(r a c)-\mathbf{2 b}$

$\mathbf{3 a}$ or $(r a c)-\mathbf{3 b}$

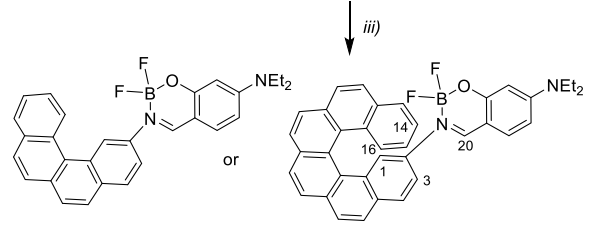

H1

(rac)-H2

Scheme 1. Synthesis of helicene-boranils $\mathbf{H 1}-\mathrm{H} 2$ from helicene-boronates 1a1b. I) $\mathrm{NaN}_{3}, \mathrm{CuSO}_{4} \cdot 5 \mathrm{H}_{2} \mathrm{O}, \mathrm{MeOH}$, reflux, $19 \mathrm{hrs}$, then $\mathrm{H}_{2}, 10 \% \mathrm{Pd} / \mathrm{C}$, EtOAc rt, 24 hrs, 2a: 65\%, 2b: 75\%; ii) 4-(diethylamino)salicylaldehyde, $\mathrm{MeOH}$, reflux, 3a $18 \mathrm{hrs}, 91 \%$, 3b: 31 hrs, $93 \%$; iii) $\mathrm{BF}_{3} \cdot \mathrm{OEt}_{2}$, DIEA, $1,2-\mathrm{DCE}, 85^{\circ} \mathrm{C}, \mathbf{H 1}: 42 \mathrm{hrs}$, $75 \%$, (rac)-H2: $24 \mathrm{hrs}, 75 \%$.

Following the same approach, [6]helicene-2,15-bis-pinacolboronate 1c was first prepared according to Scheme 2, i.e. in two steps involving a Wittig reaction between 4-formylphenylboronic acid pinacol ester $\mathbf{4}$ and (2,7-naphthalenedimethylene)bis[triphenylphosphonium-bromide] ${ }^{[19 a]} \mathbf{5}$ (58\% yield based on recovered phosphonium salt, see Supplementary Information), followed by an oxidative photocyclization reaction. Note that 1c has also been recently synthesized using another strategy from 2,15-bis-bromo-carbo[6]helicene. ${ }^{[19 b]}$ The helicenic aniline $\mathbf{2 c}$ was then prepared in a $67 \%$ overall yield by copper-catalyzed azidation using copper sulfate in refluxing methanol and hydrogenation with $\mathrm{H}_{2}$ in the presence of $\mathrm{Pd} / \mathrm{C}$. Refluxing $2 \mathrm{c}$ with 4-(diethylamino)salicylaldehyde in methanol for 22 hours afforded the anil, which was converted to $\mathbf{H} \mathbf{3}$ ( $91 \%$ yield) as previously described for $\mathbf{3 a - b}$.

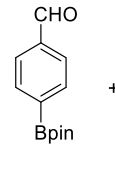

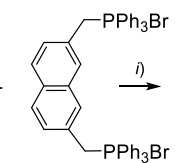

6

5

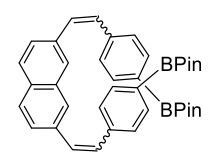

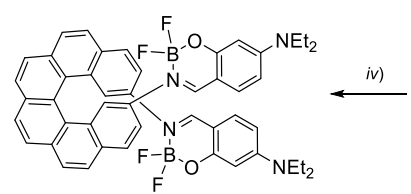

(rac) $-\mathrm{H} 3$

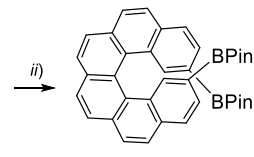

(rac)-1c (rac)-2c

Scheme 2. Synthesis of racemic boranil H3. I) $n$-BuLi, THF, Ar, rt, $3 \mathrm{hrs}, 58 \%$; ii) $h v, \mathrm{I}_{2}$, propylene oxide, toluene, Ar, $18 \mathrm{hrs}, 57 \%$; iii) $\mathrm{NaN}_{3}, \mathrm{CuSO}_{4} \cdot 5 \mathrm{H}_{2} \mathrm{O}$, $\mathrm{MeOH}, 40^{\circ} \mathrm{C}, 27 \mathrm{hrs}$, then $\mathrm{H}_{2}, 10 \% \mathrm{Pd} / \mathrm{C}$, EtOAc rt, $24 \mathrm{hrs}, 67 \%$; iv) 4(diethylamino)salicylaldehyde, $\mathrm{MeOH}$, reflux, $22 \mathrm{hrs}, 98 \%$, then $\mathrm{BF}_{3} \cdot \mathrm{OEt}_{2}$, DIEA, 1,2-DCE, $85^{\circ} \mathrm{C}, 23 \mathrm{hrs}, 91 \%$. 
The resulting novel helicenic boranils $\mathbf{H} \mathbf{1}-\mathbf{H} \mathbf{3}$ were then fully characterized by NMR and mass spectrometry (see Supplementary Information). While the ${ }^{1} \mathrm{H}$ and ${ }^{13} \mathrm{C}$ NMR spectra display the typical, characteristic signals coming from both the helicene and boranil units, these compounds show very informative ${ }^{11} \mathrm{~B}$ NMR and ${ }^{19} \mathrm{~F}$ NMR (see Table 1 and Supplementary Information). Indeed, H1 displays two chemically and magnetically equivalent fluorine atoms that resonate at $136.5 \mathrm{ppm}$ and demonstrate similar F-B coupling constants $\left({ }^{1} \mathrm{~J}_{\mathrm{F}-\mathrm{B}}\right.$ $=17.3 \mathrm{~Hz}$ ). The ${ }^{11} \mathrm{~B}$ NMR spectra show a triplet at $\delta=1.1 \mathrm{ppm}$ in agreement with a four-coordinate boron atom. By contrast, chiral H2 displays two distinct ${ }^{19} \mathrm{~F}$ NMR signals that are doublets of 1:1:1:1 quadruplets, at $-129.7\left(\mathrm{dq},{ }^{2} J_{F-F}=90 \mathrm{~Hz},{ }^{1} J_{B-F}=23 \mathrm{~Hz}\right)$ and $-143.4 \mathrm{ppm}\left({ }^{2} \mathrm{~J}_{\mathrm{F}-\mathrm{F}}=90 \mathrm{~Hz},{ }^{1} \mathrm{~J}_{\mathrm{B}-\mathrm{F}}=11.1 \mathrm{~Hz}\right)$. The corresponding ${ }^{11} \mathrm{~B}$ NMR signal demonstrates a doublet of doublets (dd) at $0.6 \mathrm{ppm}$ with different coupling constants with the two fluorine atoms. Carbo[6]helicene-2,15-bis-boranil $\mathbf{H 3}$ displays very similar features, i.e. dq signals for each fluorine and dd for the boron with the two $\mathrm{BF}_{2}$ groups being equivalent indicating $C_{2}$-symmetry of the molecule. ${ }^{[20]}$

Table 1. ${ }^{11} \mathrm{~B}$ and ${ }^{19} \mathrm{~F}$ NMR data recorded in $\mathrm{CDCl}_{3}$ at $\mathrm{rt}$ for compounds $\mathbf{H} \mathbf{1}-\mathbf{H} 3$. See also Supplementary Information.

\begin{tabular}{|c|c|c|c|c|}
\hline \multirow{2}{*}{ Compound } & \multicolumn{2}{|c|}{${ }^{11} \mathrm{~B}$} & \multicolumn{2}{c|}{${ }^{19} \mathrm{~F}$} \\
\cline { 2 - 5 } & $\begin{array}{c}\delta \text { (ppm) } \\
\text { (multiplicity) }\end{array}$ & $J_{B-F}(\mathrm{~Hz})$ & $\begin{array}{c}\delta(\mathrm{ppm}) \\
\text { (multiplicity) }\end{array}$ & $\begin{array}{c}J_{F-F} \\
(\mathrm{~Hz})\end{array}$ \\
\hline H1 & $1.1(\mathrm{t})$ & 17.3 & $-136.5(\mathrm{q})$ & - \\
\hline H2 & $0.6(\mathrm{dd})$ & 23.0 and 11.1 & $\begin{array}{c}-129.7(\mathrm{dq}) \\
\text { and }-143.4(\mathrm{dq})\end{array}$ & 90 \\
\hline H3 & $0.5(\mathrm{dd})$ & 22.7 and & $\begin{array}{c}-129.7(\mathrm{dq}) \\
\text { and }-142.7(\mathrm{dq})\end{array}$ & 89.8 \\
\hline
\end{tabular}

Enantiomeric resolution of (rac)-H2 and (rac)-H3 was performed using HPLC over chiral stationary phases, yielding $(P)$ $(+)$ and $(M)-(-)$ enantiomers of $\mathbf{H} \mathbf{2}$ and $\mathbf{H} \mathbf{3}$ with ee's higher than $99 \%$ (see Supplementary Information). Single crystals of $(+)-\mathrm{H}_{2}$ were grown by slow diffusion of pentane vapors into a $\mathrm{CH}_{2} \mathrm{Cl}_{2}$ solution and the structure was further ascertained by $\mathrm{X}$-ray diffraction crystallography. Compound (+)-H2 crystallized in the non-centro-symmetric $P 2_{1} 2_{1} 2_{1}$ space group (with the presence of $P$ enantiomers only, see Figures $3 a, b)$. The molecular structure shows a $C_{1}$ symmetry with a helicity (dihedral angle between terminal rings of the helicene) of $52.34^{\circ}$, a typical value for a carbo[6]helicene. ${ }^{[1]}$ The $\mathrm{O}-\mathrm{B}$ and the $\mathrm{B}-\mathrm{N}_{1}$ bond-lengths are 1.445 and $1.582 \AA$, respectively, which is in the range of similar 4-coordinate boron(III) derivatives. Interestingly, the helicenic and the boranil parts are linked through a $\mathrm{C}-\mathrm{N}$ single bond (with a length of $1.433 \AA$ ), which displays axial chirality due to a $B-N_{1}-C$ C' dihedral angle of $-50.51^{\circ}$, thus representing the $\left(R_{\mathrm{a}}\right)$ configuration associated with the $(P)$ stereochemistry of the carbo[6] helicene fragment. There is therefore an interesting chiral induction from the helicenic part to the axial chirality in the solid state. This can be explained by the position of the more sterically hindered $\mathrm{BF}_{2}$ group away from the helix and the existence of a $\mathrm{CH}-\pi$ interaction between the proton of the $\mathrm{CH}=\mathrm{N}$ imine and the external terminal ring of the carbo[6]helicene (Figure $3 \mathrm{a}, \mathrm{H}$ centroid distance: $2.771 \AA$ ) that 'locks' the structure into a closed form in the crystal. Finally, intermolecular $\pi-\pi$ stacking interactions (Figure $3 \mathrm{~b}$ ) are observed in the molecular packing of homochiral dimers. Note that the molecular geometry of $\mathbf{H} \mathbf{2}$ observed in its crystal structure may not necessarily be dominant in solution, as a careful analysis of the NOESY spectrum of this compound showed that the proton $\mathrm{H}^{20}$ (of the $\mathrm{CH}=\mathrm{N}$ imine) correlates with $\mathrm{H}^{13}$ and $\mathrm{H}^{14}$ (other extremity of the helicene) and with both $\mathrm{H}^{1}$ and $\mathrm{H}^{3}$ (see Figures $\mathrm{S} 1.16 \mathrm{a}-\mathrm{b}$ ), thus suggesting the fast rotation around the $\mathrm{C}^{2} \mathrm{~N}$ bound (in the NMR timescale). Similar conclusion holds also for $\mathbf{H 3}$, for which the analogous correlation of protons in the NOESY spectrum is seen $\left(\mathrm{H}^{12}\right.$ with $\mathrm{H}^{1}, \mathrm{H}^{3}$ and $\mathrm{H}^{4}$, see Figures $\mathrm{S} 1.37 \mathrm{a}$ and $\mathrm{b}$ ).

Stereochemical and structural preferences for heliceneboranils $\mathbf{H 1}, \mathbf{H} 2$, and $\mathbf{H 3}$ in solution were also examined with quantum-chemical calculations. DFT geometry optimizations (BP/SV $(\mathrm{P})$ with the continuum solvent model for $\mathrm{CH}_{2} \mathrm{Cl}_{2}$, followed by BP-D3/TZVP electronic energy evaluation (for a complete description of the computational details, see SI), considered different possible diastereoisomers (based on $(P)$ helical stereochemistry associated with either $\left(R_{\mathrm{a}}\right)$ or $\left(S_{\mathrm{a}}\right)$ axial conformational chirality) with different rotamers for the relative orientation of the boranil fragment(s) and the helicene. The results (see Figure 3c and Table 2, and Figures S2.2-S2.3 and Table $\mathrm{S} 2.1$ in $\mathrm{SI}$ ) show profound energetic preferences for the $\mathbf{H} 2$ and H3 structures demonstrating a combination of the $(P)$ and $\left(R_{\mathrm{a}}\right)$ configurations stabilized by the intramolecular $\mathrm{CH}-\pi$ boranilhelicene interaction, labelled in the following as $\left(P, R_{\mathrm{a}}\right)-\mathrm{H} 2-\mathrm{I}$ and $\left(P, R_{\mathrm{a}}, R_{\mathrm{a}}\right)$-H3-I. Coexistence of other diastereoisomeric structures in solution mixture, such as for example $\left(P, S_{\mathrm{a}}\right)$-H2-II or (of mixed axial chirality) $\left(P, R_{\mathrm{a}}, S_{\mathrm{a}}\right)-\mathrm{H} 3-\mathrm{II}$, is however quite likely as their energy values were found to be relatively close to those computed for the corresponding structures I.A-n energetic barrier for a rotation around the boranil-helicene bond is expected to be low, resulting in the overall high molecular flexibility of the systems. All this correctly reflects the results of the experimental (X-ray diffraction crystallography and NMR) studies presented above. For the [4] helicene-boranil $\mathbf{H} \mathbf{1}$ a roughly equal mixture of possible diastereoisomers is expected based on the calculated data (see Supplementary Information). 
a)

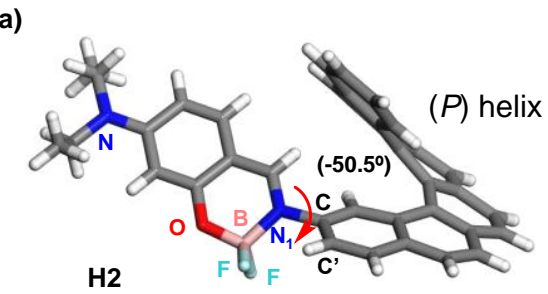

$\left(R_{\mathrm{a}}\right)$ axial chirality

b)

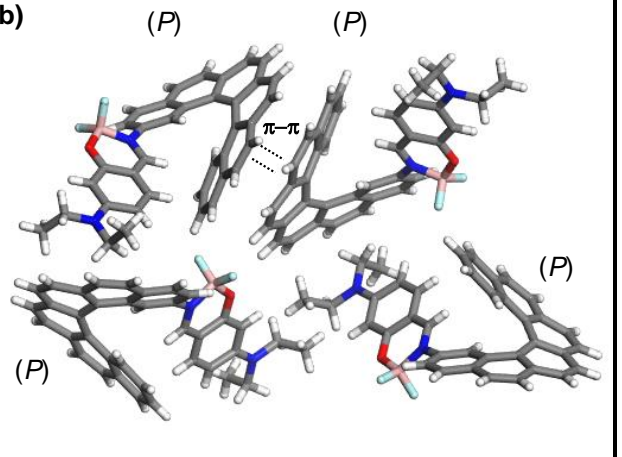

c)

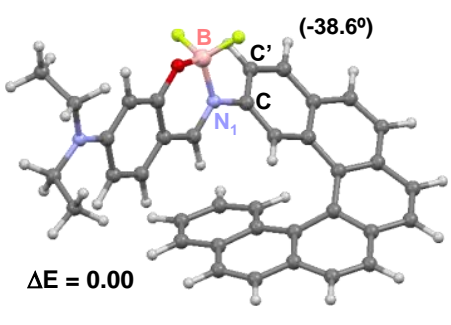

$\left(P, R_{\mathrm{a}}\right)-\mathrm{H} 2-\mathrm{I}$

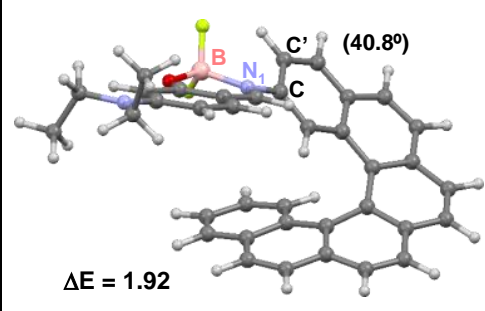

$\left(P, S_{\mathrm{a}}\right)-\mathbf{H} \mathbf{2}-\mathrm{II}$
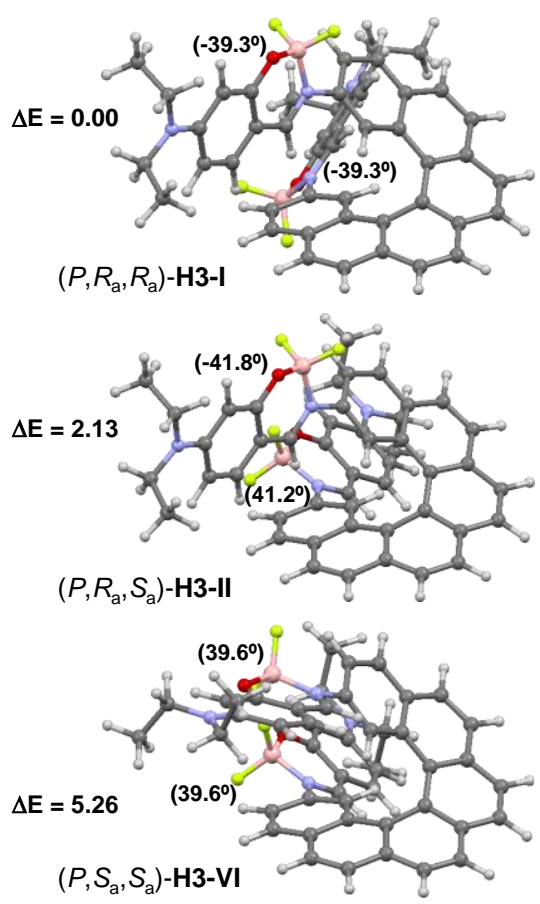

Figure 3. a) X-ray diffraction structure of $(P)-(+)-\mathbf{H} 2$ with $\left(R_{\mathrm{a}}\right)$ axial chirality highlighted along with b) its supramolecular arrangement in the crystal. c) Selected optimized (BP/SV(P) with the continuum solvent model for $\mathrm{CH}_{2} \mathrm{Cl}_{2}$ ) structures of $\mathbf{H} \mathbf{2}$ (left) and $\mathbf{H 3}$ (right). Compare with Table 2 and see Supplementary Information for a full set of data. Values listed are the corresponding relative energies $\Delta E$ (in $\mathrm{kcal} / \mathrm{mol}$ ) calculated with BP-D3/TZVP and the B-N $\mathrm{N}_{1}-\mathrm{C}_{-}-\mathrm{C}^{\prime}$ dihedral angles (provided in parentheses).

Table 2. Summary of computed $(\mathrm{BP} / \mathrm{SV}(\mathrm{P})$ with the continuum solvent model for $\mathrm{CH}_{2} \mathrm{Cl}_{2}$ ) rotamer structures for helicene-boranils $\mathbf{H 2}$ and H3: B- $\mathrm{N}_{1}-\mathrm{C}-\mathrm{C}^{\prime}$ dihedral angles as defined in Figure $3\left(\angle\right.$, in $\left.^{\circ}\right)$ along with relative energies $(\Delta E$, in $\mathrm{kcal} / \mathrm{mol}$ ) calculated with BP-D3/TZVP and the corresponding Boltzmann populations at $25^{\circ} \mathrm{C}\left(n_{\mathrm{B}}\right.$, in \%). For structures visualization, see Figure 3 and Supplementary Information.

\begin{tabular}{|c|c|c|c|c|}
\hline \multicolumn{2}{|c|}{ Structure } & $\angle$ & $\Delta E$ & $n_{\mathrm{B}}$ \\
\hline \multirow{4}{*}{ 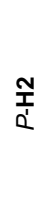 } & $\left(P, R_{\mathrm{a}}\right)-\mathrm{I}$ & -38.64 & 0.00 & 94.6 \\
\hline & $\left(P, S_{\mathrm{a}}\right)-\mathrm{II}$ & 40.84 & 1.92 & 3.7 \\
\hline & $\left(P, R_{\mathrm{a}}\right)-\mathrm{III}$ & -136.69 & 2.40 & 1.6 \\
\hline & $\left(P, S_{\mathrm{a}}\right)-\mathrm{IV}$ & 136.75 & 3.94 & 0.1 \\
\hline \multirow{7}{*}{$\frac{\mathbb{m}}{Q^{\prime}}$} & $\left(P, R_{\mathrm{a}}, R_{\mathrm{a}}\right)-\mathrm{I}$ & $-39.34 /-39.34$ & 0.00 & 93.2 \\
\hline & $\left(P, R_{\mathrm{a}}, S_{\mathrm{a}}\right)-\mathrm{II}$ & $-41.83 / 41.23$ & 2.13 & 2.6 \\
\hline & $\left(P, S_{\mathrm{a}}, R_{\mathrm{a}}\right)-\mathrm{III}$ & $42.70 /-131.51$ & 2.20 & 2.2 \\
\hline & $\left(P, R_{\mathrm{a}}, R_{\mathrm{a}}\right)$-IV & $-38.01 /-136.01$ & 2.28 & 2.0 \\
\hline & $\left(P, R_{\mathrm{a}}, R_{\mathrm{a}}\right)-\mathrm{V}$ & $-136.88 /-136.88$ & 4.83 & 0.0 \\
\hline & $\left(P, S_{\mathrm{a}}, S_{\mathrm{a}}\right)-\mathrm{V} \mathrm{l}$ & 39.59 / 39.59 & 5.26 & 0.0 \\
\hline & $\left(P, S_{\mathrm{a}}, S_{\mathrm{a}}\right)-\mathrm{VII}$ & $138.20 / 142.38$ & 7.14 & 0.0 \\
\hline
\end{tabular}

\section{Photophysical properties: UV-vis spectroscopy}

The UV-vis spectra of the [ $n$ ] helicene-boranils $\mathbf{H} 1-\mathrm{H} 3$ were measured in $\mathrm{CH}_{2} \mathrm{Cl}_{2}$ solution at concentrations ca. $10^{-5} \mathrm{M}$ and they are presented in Figure 4a. The [4]helicene-boranil H1 system displays two main wide and strong bands comprising: I) two signals at 270 and $284 \mathrm{~nm}(\varepsilon \sim 30000)^{\varepsilon}$ accompanied with broad structuration and ii) an even stronger signal at $415 \mathrm{~nm}(\varepsilon \sim$ $38000)$. Reflecting an increase in the $\pi$-electron system, the [6] helicene-mono-boranil $\mathbf{H} \mathbf{2}$ and bis-boranil $\mathbf{H} \mathbf{3}$ exhibit stronger
UV-vis responses as compared to $\mathbf{H} \mathbf{1}$, with three main sets of bands that include: $I$ ) a set of two signals at 246 and $255 \mathrm{~nm}(\varepsilon \sim$ $53000)$ for $\mathbf{H 2}$, which are weaker in $\mathbf{H} \mathbf{3}$ (243-255 nm, $\varepsilon \sim 33000)$, ii) a set of three signals at 305,333 and $351 \mathrm{~nm}(\varepsilon=22000-29100)$ for H2, which appear at 305, 343 and $356 \mathrm{~nm}(\varepsilon=19000-27500)$ for H3, and iii) a strong signal at $409 \mathrm{~nm}(\varepsilon=50000)$ with shoulders at 390 and $423 \mathrm{~nm}$ for $\mathbf{H} 2$ that corresponds to a strongly enhanced one at $412 \mathrm{~nm}(\varepsilon=70000)$ with shoulders at 393 and $433 \mathrm{~nm}$ for $\mathbf{H 3}$.

To shed some light on the electronic origin of these bands, time-dependent DFT (TD-DFT) calculations were then performed. See Supplementary Information for all computational details and a full set of computed data. The simulated UV-vis spectra of H1, H2, and H3 do not differ much for different diastereomeric structures and visibly fail to reproduce experimental relative intensities of the lowest-energy band for $\mathbf{H} \mathbf{1}$ vs. H2-H3 (overestimating the intensity for $\mathbf{H} \mathbf{1}$ ) and of the two bands around $330 \mathrm{~nm}$ and $\mathbf{4 1 0} \mathrm{nm}$ for $\mathbf{H} \mathbf{2}$ and $\mathbf{H} \mathbf{3}$ (overestimating the intensity for the higher-energy -shorter-wavelength- band); see the discussion below. However, other important spectral features observed in the experiments (such as relative and absolute energetic positions of the bands along with a substantial increase in the low-energy absorption intensity when going from $\mathbf{H} \mathbf{2}$ to $\mathbf{H} \mathbf{3}$ ) appear to be overall well-described by theory (PBE0/SV(P) with a continuum solvent model for $\mathrm{CH}_{2} \mathrm{Cl}_{2}$, see Figure S2.7), enabling assignment of the particular bands. Namely, analysis of molecular orbital (MO) pair contributions to selected excitations for H1, H2, and $\mathbf{H} \mathbf{3}$ shows that the high-energy intense band of these systems observed experimentally around $275 \mathrm{~nm}$ for $\mathbf{H 1}$ and $250 \mathrm{~nm}$ for H2 and $\mathbf{H} 3$ originates from predominatly helicene-centered $\pi-\pi^{\star}$ excitations with contributions from helicene $\rightarrow$ boranil and boranil $\rightarrow$ helicene charge-transfer (CT) transitions. The UV-vis intensity around $330 \mathrm{~nm}$ can be, on the other hand, assigned to a 
WILEY-VCH

combination of mainly boranil $\rightarrow$ helicene and helicene $\rightarrow$ boranil CTs mixed with $\pi-\pi^{*}$ transitions within helicene fragment. Such assignments account for strong enhancement in absorption observed experimentally in this spectral range for the more $\pi$ extended [6]helicene-based $\mathbf{H} \mathbf{2}$ and $\mathbf{H} \mathbf{3}$ compared to the [4] helicene derivative H1. Finally, the computations indicate that the lowest-energy band of all three systems, centered around 410 $\mathrm{nm}$, is due to excitations involving highest occupied $(\mathrm{HO})$ and lowest unoccupied (LU) MOs (HOMO / LUMO for H1, H2; HOMO1, HOMO / LUMO, LUMO+1 for H3; see Figure 4c and Supplementary Information) and accordingly corresponding to $\pi$ $\pi^{*}$ transitions within the boranil fragment(s) $\pi$-conjugated with the adjacent helicene rings. As the orbitals are centered in slightly different parts of the $\pi$-electron system, the excitations demonstrate also some CT signature.

Note that HOMO-1, HOMO, LUMO, and LUMO+1 of $\mathrm{H} 3$ have electronic density extended over both boranil substituents and partially also over the helicene, but in-phase and out-of-phase linear combinations may be taken where electronic density localizes on one boranil (and adjacent helicene rings) fragment. While in the case of $\mathbf{H} \mathbf{1}$ and $\mathbf{H} \mathbf{2}$, one intense excitation contributes to this band (no. 1 calculated at respectively ca. $400 \mathrm{~nm}$ and 410 $\mathrm{nm}$ ), for $\mathbf{H} \mathbf{3}$ an intense pair of excitations was computed in this spectral region (no. 1 at ca. $420 \mathrm{~nm}$ and no. 2 at ca. $400 \mathrm{~nm}$ ) that may indicate exciton coupling between the two boranil-helicene $\pi-\pi^{*}$ transitions, similar to what we previously showed for pushpull helicenic diketopyrrolopyrrole systems. ${ }^{[21 a]}$ This can rationalize a red-shift of the lowest-energy absorption band and an increase in its intensity observed experimentally for $\mathbf{H} 3$ as compared to $\mathbf{H} \mathbf{2}$.

\section{Chiroptical properties: electronic circular dichroism, optical rotation}

The electronic circular dichroism (ECD) spectra and optical rotation $(\mathrm{OR})$ values of the [6] helicenic derivatives $\mathbf{H} 2$ and $\mathbf{H 3}$ were also examined (Figure 4, Table S1.1, Supplementary Information). ${ }^{£}$ Both systems display strong specific rotation values $\left([\alpha]_{D}^{25}=+3900\right.$ and +3550 for $(P)-\mathbf{H} 2$ and $(P)-\mathbf{H} 3$, respectively) that are similar to other carbo[6]helicenes. ${ }^{[1]}$ As depicted in Figure $4 \mathrm{~b}$, the $(M)$ and $(P)$ enantiomers display the expected mirrorimage ECD spectra. The three sets of bands observed in UV-vis spectra are ECD active in both $\mathbf{H} 2$ and $\mathbf{H} 3$. For instance, $(P)-\mathbf{H} 2$ displays $i)$ a strong negative band at $245 \mathrm{~nm}(\Delta \varepsilon=-244)$ accompanied with two weaker ones at $265(-79)$ and $290 \mathrm{~nm}(-$ $29)$, ii) two positive bands of moderate intensity at $319(+57)$ and $329 \mathrm{~nm}(+51)$, and iii) two strong positive bands at $407(+98)$ and $417 \mathrm{~nm}(+103)$. Overall the ECD spectral envelope of this [6] helicene-based system is strikingly different from those measured for the classical helicenic compounds such as nonsubstituted carbo[n] helicenes. ${ }^{[1]}$ This is also the case for the helicene-bis-boranil $\mathbf{H} \mathbf{3}$, whose $(P)$ enantiomer exhibits overall the same characteristic bands in its ECD spectrum as $(P)-\mathbf{H} 2$, but with different relative intensities or signs and a clear red-shift of the lower-energy bands, i.e. I) a weaker negative band at $244(-143)$ accompanied with other ones at $277(-48), 284(-41)$, and $307 \mathrm{~nm}$ $(-11), i i)$ three negative bands of moderate intensity at $343(-44)$, $355(-39)$ and $389 \mathrm{~nm}(-35)$, and iii) one strong positive band at $435 \mathrm{~nm}(+197)$.
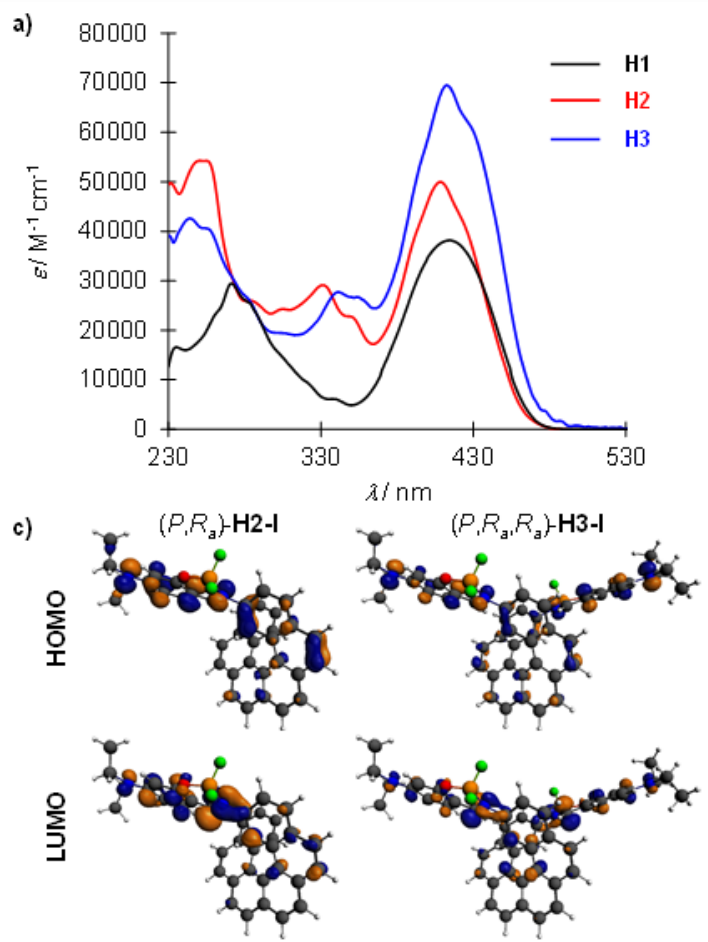

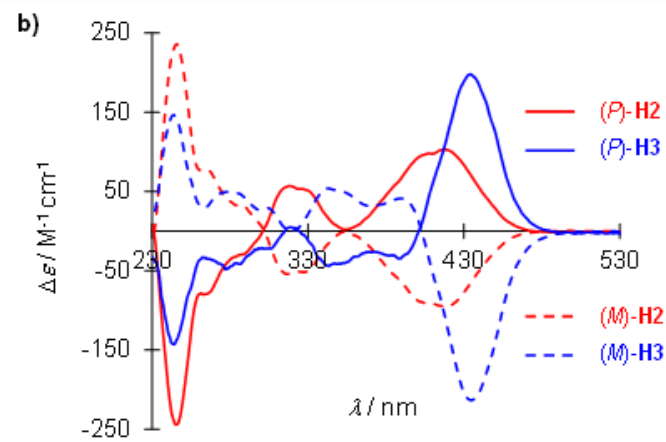

d)

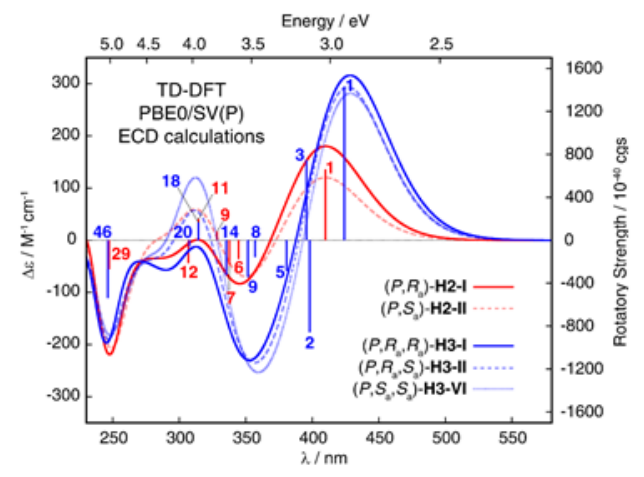

Figure 4. Experimental a) UV-vis of $\mathbf{H} 1-\mathbf{H} 3$ and b) ECD spectra of $(P)$ and $(M)$ enantiomers of $\mathbf{H} 2$ and $\mathbf{H} 3\left(\mathrm{CH}_{2} \mathrm{Cl}_{2}, C \sim 10^{-5} \mathrm{M}\right)$. C) Isosurfaces $( \pm 0.04$ au) of frontier MOs of the lowest-energy computed $\mathbf{H} \mathbf{2}$ and $\mathbf{H} \mathbf{3}$ structures. d) Simulated ECD spectra for representative $(P)$ diastereoisomers of $\mathbf{H} \mathbf{2}$ and $\mathbf{H} \mathbf{3}$ with selected calculated excitation energies and rotatory strengths (for structures I) indicated as "stick" spectra. See Supplementary Information for a full set of data. 


\section{WILEY-VCH}

The TD-DFT-simulated ${ }^{[22]}$ (PBE0/SV(P) with a continuum solvent model for $\mathrm{CH}_{2} \mathrm{Cl}_{2}$ ) ECD spectra for selected $\mathbf{H} \mathbf{2}$ and $\mathbf{H} 3$ diastereomeric structures are presented in Figure 4d; see also Supplementary Information for additional calculated data. ECD spectral envelope obtained for the energetically most preferred conformer $\left(P, R_{\mathrm{a}}\right)$-H2-I, as indicated by DFT, (see Figure 3c and Table 2), resembles the experimental ones but with "too negative" intensity between ca. 375 and $300 \mathrm{~nm}$. The corresponding $\left(P, S_{\mathrm{a}}\right)$ H2-II structure (of relatively low energy) demonstrates very similar ECD spectrum but with a decreased intensity of the first lowenergy positive band and, more importantly, with appearance of a positive band of moderate intensity around $325 \mathrm{~nm}$ that matches well the second positive band observed for this compound in the experiment. It is worth mentioning that the spectral data obtained for other optimized $\mathbf{H} \mathbf{2}$ geometries clearly confirm a high sensitivity of the ECD intensity in the low- and medium-energy range to the rotamer structure and particularly to its axial chirality (see Figure S2.4 and Figure 4d), with the $\left(P, S_{\mathrm{a}}\right)$ diastereoisomers emerging as predominantly responsible for the positive ECD signal measured at ca. $325 \mathrm{~nm}$. This further supports the coexistence of various $\mathbf{H} 2$ structures of both $\left(R_{\mathrm{a}}\right)$ and $\left(S_{\mathrm{a}}\right)$ axial chirality in solution mixture also suggested based on the NMR studies (vide supra). An analysis of the dominant excitations of the simulated spectra of $\left(P, R_{\mathrm{a}}\right)-\mathbf{H} 2-\mathbf{I}$ and $\left(P, S_{\mathrm{a}}\right)$-H2-II conformers assigns the intense negative ECD band centered at ca. $250 \mathrm{~nm}$ to excitations involving predominantly, as expected, $\pi-\pi^{\star}$ transitions within the helicene moiety (e.g. excitation no. 29 calculated at $247 \mathrm{~nm}$ ), although with additional small CT contributions mostly of the boranil $\rightarrow$ helicene origin. The lowestenergy positive band measured around $410 \mathrm{~nm}$ corresponds to the HOMO-to-LUMO $\pi-\pi^{*}$ transitions centered mainly at the boranil chromophore with noticeable involvement of helicene $\pi$ orbitals electronically coupled with the boranil $\pi$-electron system (excitation no. 1 calculated at ca. $410 \mathrm{~nm}$ ). The decrease in positive ECD intensity experimentally observed at around $350 \mathrm{~nm}$ for the $(P)-\mathrm{H} 2$ enantiomer appears to originate from excitations representing a combination of predominantly boranil $\rightarrow$ helicene CTs and helicene-centered $\pi-\pi^{*}$ transitions of CT-like signature mixed with additional small contributions from helicene $\rightarrow$ boranil CTs and $\pi-\pi^{*}$ transitions within the boranil fragment (e.g. excitations nos. 6 and 7 calculated at ca. 345 and $336 \mathrm{~nm}$, respectively). The overestimation of this intensity drop observed in the computations (leading to the appearance of the negative band in the calculated spectra) is likely due to neglecting vibrational effects and / or disregarding contributions from other less-energetic (equilibrium) conformers. In the former matter, not only vibronic contributions (note that indeed both UV-vis and ECD experimental spectra for all the systems studied show vibronic fine structure), ${ }^{[23]}$ but also nonequilibrium structure effects, ${ }^{[24]}$ might be crucial here to ensure a satisfactory agreement of the simulated spectra with experiments. In particular, we speculate that vibrational bending of the boranil-helicene bond can reduce / break the electronic $\pi$-conjugation between both fragments that is expected to affect intensity of excitations within these systems. ${ }^{[25]}$ This is indeed supported by a substantial modification of the ECD intensity found for some BP+D3-optimized structures in which the boranil moiety strongly (and likely exaggeratedly) bent towards terminal rings of the helicene (see Supplementary Information). Finally, the ECD signal around $325 \mathrm{~nm}$ appears to be due to several excitations of sizable calculated rotatory strengths $(R)$ differing in sign that demonstrate mainly a mixed helicene- $/$ boranil-centered $\pi$ - $\pi^{*}$ and helicene $\rightarrow$ boranil / boranil $\rightarrow$ helicene CT character (e.g. excitations nos. $9(+), 11(+)$, and $12(-)$ calculated at ca. 328,314 , and $307 \mathrm{~nm}$, respectively); magnitudes of $R$ for these excitations are clearly dependent on a molecular structure leading to a cancellation of their ECD intensity in the simulated spectrum for $\left(P, R_{\mathrm{a}}\right)-\mathrm{H} 2-\mathrm{I}$ or an appearance of a positive intensity in the case of, for example, $\left(P, S_{\mathrm{a}}\right)$-H2-II.

As can be seen in Figure 4, the simulated ECD spectrum for the calculated lowest-energy structure $\left(P, R_{\mathrm{a}}, R_{\mathrm{a}}\right)$-H3-I (see Figure $3 \mathrm{c}$ and Table 2 ), agrees quite well with the experimental data. In particular, it correctly reproduces a red-shift and increase in intensity of the lowest-energy positive band along with appearance of more negative intensity between ca. 400 and 280 $\mathrm{nm}$ that were observed in the experimental ECD spectra of $(P)$ H3 vs. $(P)-\mathbf{H} 2$. Similarly to the mono-boranil $\mathbf{H 2}$, a visible dependence of the bands intensity in the simulated ECD spectra on the molecular structure of $\mathbf{H} \mathbf{3}$ was also noted, with $\left(S_{\mathrm{a}}\right)$ axial chirality giving its clear signature in form of a positive band centered around $325 \mathrm{~nm}$ (see Figure S2.5 and Figure 4d). Since in the experiment a weakly intense positive band was indeed observed in this spectral region, coexistence of various structures of both $\left(R_{\mathrm{a}}\right)$ and $\left(S_{\mathrm{a}}\right)$ configurations in solution might also be postulated for $\mathbf{H 3}$. The assignment of the H3 ECD spectrum is qualitatively similar to that of $\mathbf{H 2}$. Namely, predominantly boraniland helicene-centered $\pi-\pi^{*}$ transitions were found to be responsible for respectively lowest-energy positive (ca. $430 \mathrm{~nm}$ ) and highest-energy negative (ca. $240 \mathrm{~nm}$ ) bands present in the experimental spectrum (see excitations nos. 1 and 46 calculated at ca. $420 \mathrm{~nm}$ and $245 \mathrm{~nm}$ ), while the negative ECD intensity appearing between ca. 400 and $280 \mathrm{~nm}$ origin from helicene $\rightarrow$ boranil and boranil $\rightarrow$ helicene CT excitations mixed with $\pi-\pi^{*}$ transitions within boranils and helicene fragments (see e.g. excitations nos. 5, 8, 9, and 14 calculated between around 380 and $330 \mathrm{~nm}$ ). These latter excitations, demonstrating sizable negative rotatory strength values, enhanced compared to $\mathbf{H} 2$ reflecting the presence of the second boranil chromophore, lead to a very intense negative band in the simulated spectrum that is strongly overestimated compared with the experimental one likely due to similar reasons as for $\mathbf{H} \mathbf{2}$ (vide supra). As for $\mathbf{H 2}$, a sign of ECD intensity around $\mathbf{3 2 5} \mathrm{nm}$ for $\mathbf{H} \mathbf{3}$ appears to stem from a cancellation $\left(\left(P, R_{\mathrm{a}}, R_{\mathrm{a}}\right)-\mathrm{H} 3-\mathrm{I}\right)$ or enhancement $\left(\left(P, R_{\mathrm{a}}, S_{\mathrm{a}}\right)-\mathrm{H} 3-\mathrm{II}\right.$ and $\left.\left(P, S_{a}, S_{\mathrm{a}}\right)-\mathbf{H} 3-\mathbf{V} \mathbf{I}\right)$ of the underlying excitations representing a combination of mainly boranil- and helicene-centered $\pi-\pi^{*}$ transitions.

Despite the similarities between the mono-boranil $\mathbf{H} \mathbf{2}$ and bisboranil $\mathbf{H} 3$ systems, a striking difference can be noted in their lowenergy ECD-active excitations. Namely, unlike for $(P)-\mathbf{H}$ 2, for which calculations showed one intense excitation underlying the lowest-energy band in the spectrum (excitation no. 1 computed at ca. $410 \mathrm{~nm}$, vide supra), in the case of $(P)-\mathrm{H} 3$ an intense pair of excitations involving HOMO-1, HOMO, LUMO, and LUMO+1 is present in this spectral region (excitations nos. 1 and 2 at around 420 and $400 \mathrm{~nm}$, respectively) that both reveal the same (and shared with H2) predominantly boranil-centered $\pi-\pi^{*}$ character with a noticeable involvement of the helicene $\pi$-orbitals but demonstrate opposite-sign rotatory strengths $((+)$ and $(-)$ for the lower-energy and higher-energy excitation, respectively). The electronic and MO-pair assignment, large rotatory strengths and the opposite signs of these first two excitations clearly indicate exciton coupling between the electric transition dipoles of the boranil fragments grafted onto the extremities of H3, with 
WILEY-VCH

noticeable contributions from the helicene $\pi$-system, similar to what was shown by us recently for helicene-diketopyrrolopyrrole derivatives. ${ }^{[21 a]}$ It should be however noted that unlike for the helicene-diketopyrrolopyrrole systems, in the case of $(P)-\mathrm{H} 3$ higher-energy negative exciton couplet component does not appear to contribute much to the following negative band in the ECD spectrum as it seems to be efficiently suppressed by the nearby excitation with large positive rotatory strength value (excitation no. 3 calculated at ca. $395 \mathrm{~nm}$ ) corresponding to boranil-centered $\pi-\pi^{*}$ transition mixed with helicene $\rightarrow$ boranil CT.

\section{Luminescence properties}

Boranil derivatives can display appealing emission properties, notably also in the solid state, and may show AggregationInduced Emission (AIE) or Aggregation-Induced Emission Enhancement (AIEE) effects. ${ }^{[16,17,26]}$ The luminescence properties of compounds $\mathbf{H 1}-\mathbf{H} \mathbf{3}$ were thus recorded in $\mathrm{CH}_{2} \mathrm{Cl}_{2}$ at room temperature $(\mathrm{rt}, 298 \mathrm{~K})$ and in the solid state. The $\mathrm{rt}$ emission spectrum of $\mathbf{H 1}$ is displayed in Figure S1.43, showing two fluorescence signals, at 480 and $504 \mathrm{~nm}$; a quantum yield of $4 \%\left(\lambda_{\mathrm{exc}}=350 \mathrm{~nm}\right)$ was measured. The [6] helicene derivatives $\mathrm{H} 2$ and $\mathbf{H} \mathbf{3}$ also display two main fluorescence signals, at respectively 485-515 nm (Figure 5a) and 493-520 nm (Figure 5b), thus only slightly red-shifted compared to $\mathbf{H 1}$, but with visibly enhanced quantum yields of $30 \%$ and $20 \%$; these values are quite high for [6] helicenes ${ }^{[1]}$ and consistent with the results for other boron derivatives. ${ }^{[9-12,16,17]}$ Note that the emission spectra were also measured in other solvents but no solvatochromism was observed. Finally, the luminescence properties of $\mathbf{H} \mathbf{2}$ and $\mathbf{H} \mathbf{3}$ were examined in powders and quantum yields were found to be $8 \%$ at $519 \mathrm{~nm}$ for the mono-boranil and almost zero for the bis-boranil derivative. Note that AIE enhancement (AIEE) was studied in water/THF mixtures but no effect was observed for these systems.

Similar luminescence properties of $\mathbf{H} \mathbf{1}-\mathbf{H} \mathbf{3}$ along with the similarity of their corresponding lowest-energy absorption may indicate fundamentally identical nature of the emitting $S_{1}$ state for all three systems. This was indeed ascertained using TD-DFT calculations (PBE0/SV $(\mathrm{P})$ with a continuum solvent model for $\mathrm{CH}_{2} \mathrm{Cl}_{2}$ ). The computations involving $\mathrm{S}_{1}$ excited-state geometry optimizations reproduced correctly experimental energetic positions of the emission maxima and their overall slight red-shift when going from $\mathbf{H} \mathbf{1}$ to $\mathbf{H} \mathbf{2}$ to $\mathbf{H} \mathbf{3}$ and confirmed that in each case $S_{1} \rightarrow S_{0}$ fluorescence transition is of the boranil-centered $\pi-\pi^{*}$ character with some helicene $\rightarrow$ boranil CT signature (see Table S2.5 and Figure S2.15). Overall small CT component in the emission is in line with the rather minor effect of a solvent polarity on the experimentally observed fluorescence spectra of these compounds.

\section{Circularly polarized luminescence}

Helicenes are known to exhibit efficient circularly polarized fluorescence or phosphorescence activity, which makes them appealing for incorporation into OLEDs as circularly polarized electroluminescent materials. ${ }^{[2]}$ The CPL spectra of $(P)$ and $(M)$ enantiomers of $\mathbf{H} \mathbf{2}$ and $\mathbf{H} \mathbf{3}$ derivatives and of their racemic samples were thus recorded in $\mathrm{CH}_{2} \mathrm{Cl}_{2}$ at rt. As expected, the enantiomers revealed mirror-image relationships, while the racemic samples exhibited no CPL activity. Regarding the dissymmetry factors, which reflect the percentage of circularly polarized emitted light $\left(g_{\text {lum }}=2\left(L_{L}-I_{R}\right) /\left(L_{L}+I_{R}\right)\right)$, we obtained $g_{\text {lum }}$ of $-1.29 \times 10^{-3} /+1.2 \times 10^{-3}$ for $\mathbf{H} 2$ and $-2.5 \times 10^{-3} /+2.5 \times 10^{-3}$ for $\mathbf{H} 3$, for $(M) /(P)$ enantiomers, respectively. The fact that $\mathbf{H} \mathbf{3}$ displays higher glum values as compared to $\mathbf{H} \mathbf{2}$ is in agreement with our previous results on helicene-diketopyrrolopyrrole and -naphthalimide derivatives. ${ }^{[21]}$ In particular, a clear reminiscence to the former systems can be noted here, with the bis-boranil derivative $\mathbf{H} \mathbf{3}$ showing exciton coupling chirality based on a typical low-energy substituent-centered excition couplet which induces enhanced chiroptical activity and stronger CPL (vide supra). The calculations correctly reproduced an increase (roughly doubling) of the glum values for $\mathbf{H} \mathbf{3}$ vs. $\mathbf{H} \mathbf{2}$ and linked it predominantly to an increase in rotatory strength of $S_{1} \rightarrow S_{0}$ fluorescence transition for the bis-boranil system. The analysis showed that this enhancement can be in turn traced back to a more beneficial orientation (an increased deviation of the angle from $90^{\circ}$ ) between the underlying electric and magnetic transition dipole moments observed for $\mathbf{H} \mathbf{3}$ as compared to $\mathbf{H} \mathbf{2}$ (see Table S2.6 and Figure S2.16). This might indeed be a reflection of the exciton coupling effect in the excited state of $\mathbf{H 3}$ with the resulting lower-energy couplet's component representing the $S_{1}$ state being the emitting one. Finally, it was appealing to see whether these derivatives display CPL activity in the solid state. Indeed, spin-coated films of $(P)$ - and $(M)-\mathrm{H} \mathbf{1}(0.2 \%$ in weight in PMMA films) gave nice mirrorimage CPL signals with maximum emission at $490 \mathrm{~nm}$ and $g_{\text {lum }}$ values similar to the solution state (Figure $5 \mathrm{c}$ ), i. e. around $\pm 10^{-3}$. Satisfyingly, these chiral films appeared fully isotropic (see Supplementary Information).

\section{Conclusion}

We have prepared a new family of boron-substituted helicene derivatives that enriches both helicenes and boranils chemistry, namely carbo[4]helicene-2-mono-boranil (H1) and carbo[6]helicene-2-mono- and -2,15-bis-boranils (H2 and H3, respectively), which display fluorescence emission in solution. Furthermore, enantiopure $\mathbf{H} \mathbf{2}$ and $\mathbf{H} \mathbf{3}$ systems also show efficient circularly polarized luminescence, with absolute glum values up to $2.5 \times 10^{-3}$ demonstrated by the bis-boranil derivative thanks to the exciton coupling effect. The X-ray structure analysis of $\mathbf{H} 2$ revealed an interesting chiral induction from the helicenic part to the axial chirality that arises due to the presence of a $\mathrm{CH}-\pi$ interaction between a proton of the boranil unit and the carbo[6] helicene core which 'locks' the structure into a closed form of energetically preferred $\left(P, R_{\mathrm{a}}\right) /\left(M, S_{\mathrm{a}}\right)$ stereochemistry in the solid state. As a result, the system keeps its CPL activity in PMMA films. In the solution, coexistence of various structures of both $\left(R_{\mathrm{a}}\right)$ and $\left(S_{\mathrm{a}}\right)$ axial chirality is however expected based on both experimental and computational results. These structural aspects put forward novel features in the domain of helicenes and might inspire further research aiming at preserving and controlling specific axially chiral conformations also in solution.

\section{Acknowledgements}

We acknowledge the Centre National de la Recherche Scientifique (CNRS) and the University of Rennes. This work was supported by the Agence Nationale de la Recherche (ANR-16CE07-0019 "Hel-NHC" grant). M.S.-H. thanks the PL-Grid Infrastructure and the ACC Cyfronet AGH in Krakow, Poland for 
providing computational resources. Dr. Ludovic Favereau is warmly thanked for fruitful discussions.

a)

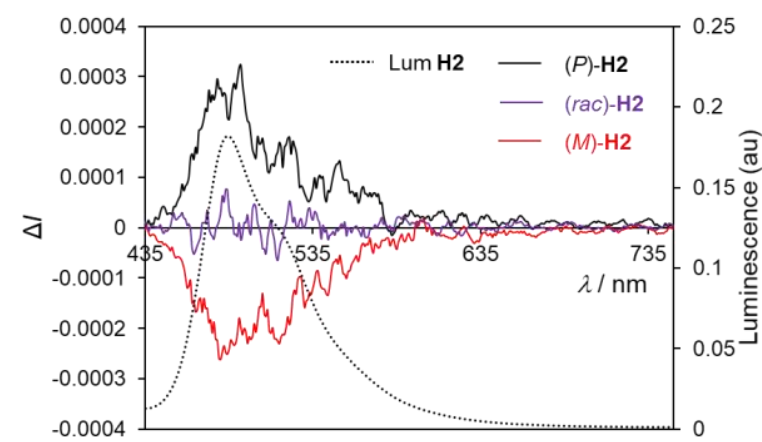

b)

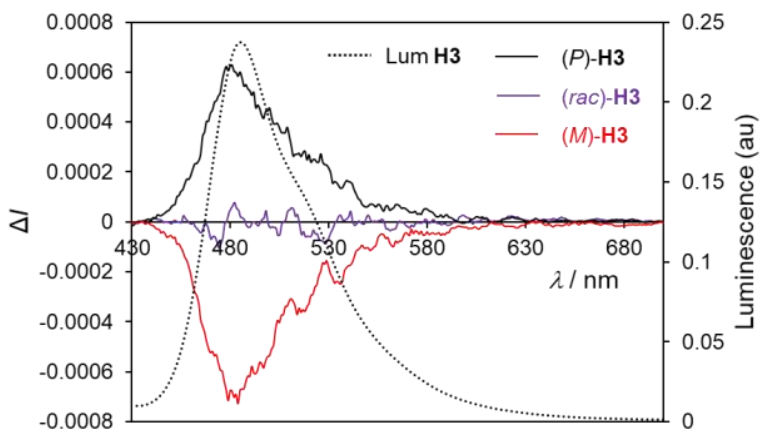

c)

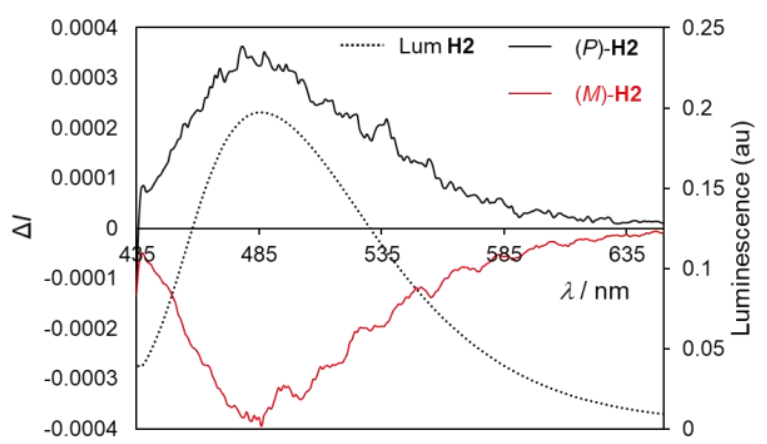

Figure 5. Experimental emission and CPL spectra of $(P)$ and $(M)$ enantiomers of a) $\mathbf{H} 2$ and b) $\mathbf{H} 3$ in $\mathrm{CH}_{2} \mathrm{Cl}_{2}$ at $C \sim 10^{-5} \mathrm{M}$ and rt and c) $\mathbf{H} 2$ in $\mathrm{PMMA}$. Excitation wavelengths are 390 and $385 \mathrm{~nm}$, for $\mathbf{H} \mathbf{2}$ and $\mathbf{H 3}$, respectively.

Keywords: boranil; chirality; CPL; helicene; quantum chemistry

\section{Notes}

E All $\varepsilon$ and $\Delta \varepsilon$ values in this work are given in units of $\mathrm{M}^{-1} \mathrm{~cm}^{-1}$, and all specific rotations in degree $\left[\mathrm{dm}\left(\mathrm{g} \mathrm{cm}^{-3}\right)\right]^{-1}$.

\section{References}

[1] a) Y. Shen, C.-F. Chen, Chem. Rev. 2012, 112, 1463-1535; b) M. Gingras, Chem. Soc. Rev. 2013, 42, 1051-1095; c) Y. S. C.-F. Chen, Helicenes Chemistry: From Synthesis to Applications, Springer, Berlin, 2017.

[2] a) W.-L. Zhao, M. Li, H.-Y. Lu, C.-F. Chen, Chem. Commun. 2019, 55, 13793-13803; b) J. Crassous in "Circularly Polarized Luminescence of Isolated Small Organic Molecules", T. Mori (ed.), Springer, 2020, chap. 4, pp 53-97.

[3] a) F. S. Richardson, J. P. Riehl, Chem. Rev. 1977, 77, 773-792; b) J. P. Riehl, F. S. Richardson, Chem. Rev. 1986, 86, 1-16; c) J. Kumar, T. Nakashima, T. Kawai, J. Phys. Chem. Lett. 2015, 6, 3445-3452; d) B. Kunnen, C. Macdonald, A. Doronin, S. Jacques, M. Eccles, I. Meglinski, J. Biophotonics, 2015, 8, 317-323; e) E. M. Sánchez-Carnerero, A. R. Agarrabeitia, F. Moreno, B. L. Maroto, G. Muller, M. J. Ortiz, S. de la Moya, Chem. Eur. J. 2015, 21, 13488-13500; f) J. Han, S. Guo, H. Lu, S. Liu, Q. Zhao,W. Huang, Adv. Opt. Mater. 2018, 6, 1800538.

[4] a) F. Zinna, L. Di Bari, Chirality 2015, 27, 1-13; b) R. Carr, N. H. Evans, D. Parker, Chem. Soc. Rev. 2012, 41, 7673-7686; c) G. Muller, Dalton Trans. 2009, 9692-9707.
[5] Selected examples: a) L. Norel, M. Rudolph, N. Vanthuyne, J. A. G. Williams, C. Lescop, C. Roussel, J. Autschbach, J. Crassous, R. Réau Angew. Chem. Int. Ed. 2010, 49, 99-102; b) K. Nakamura, S. Furumi, M. Takeuchi, T. Shibuya, K. Tanaka, J. Am. Chem. Soc. 2014, 136, 55555558 ; c) K. Murayama, Y. Oike, S. Furumi, M. Takeuchi, K. Noguchi, K. Tanaka, Eur. J. Org. Chem. 2015, 1409-1414; d) C. Schaack, L. Arrico E. Sidler, M. Górecki, L. Di Bari, F. Diederich, Chem. Eur. J. 2019, 25 8003-8007.

[6] K. Dhbaibi, L. Favereau, J. Crassous, Chem. Rev. 2019, 119, 8846-8953.

[7] a) C. Shen, M. Srebro-Hooper, M. Jean, N. Vanthuyne, L. Toupet, J. A G. Williams, A. R. Torres, A. J. Riives, G. Muller, J. Autschbach, J Crassous, Chem. Eur. J. 2017, 23, 407-418. For longer analogues see: b) J. Full, S. P. Panchal, J. Götz, A.-M. Krause, A. Nowak-Król, Angew. Chem. 2021, 60, 4350-4357.

[8] Z. Domínguez, R. López-Rodríguez, E. Álvarez, S. Abbate, G. Longhi, U. Pischel, A. Ros, Chem. Eur. J. 2018, 24, 12660-12668

[9] T. Katayama, S. Nakatsuka, H. Hirai, N. Yasuda, J. Kumar, T. Kawai, T. Hatakeyama, J. Am. Chem. Soc. 2016, 138, 5210-5213.

[10] a) C. Maeda, K. Nagahata, T. Shirakawa, T. Ema, Angew. Chem. Int. Ed. 2020, 59, 7813-7817; b) E. M. Sánchez-Carnerero, F. Moreno, B. L. Maroto, A. R. Agarrabeitia, M. J. Ortiz, B. G. Vo, G. Muller, S. de la Moya, J. Am. Chem. Soc. 2014, 136, 3346-3349.

[11] P. M. Lorente, A. Wallabregue, F. Zinna, C. Besnard, L. Di Bari, J. Lacour, Org. Biomol. Chem. 2020, 18, 7677-7684.

[12] Z.-H. Zhao, X. Liang, M.-X. He, M.-Y. Zhang, C.-H. Zhao, Org. Lett. 2019 21, 9569-9573.

[13] For recent examples, see: a) R. P. Nandi, P. Sudhakar, N. K Kalluvettukuzhy, P. Thilagar, Chem. Eur. J. 2020, 26, 16306-16317; b) S. Agren, M. Chaabene, A.-R. Allouche, R. Ben Chaabane, M. Lahcinie M. H. V. Baouab, Appl. Organomet. Chem. 2020, 34, e5764; c) A. Ren, D. Zhu, Y. Luo, J. Mol. Struct. 2020, 1209, 127914; d) H. H. T. Al-Sharif R. Ziessel, P. G. Waddell, C. Dixon, A. Harriman, J. Phys. Chem. A 2020 124, 2160-2172; e) N. Zhao, C. Ma, W. Yang, W. Yin, J. Wei, N. Li, Chem. Comm. 2019, 55, 8494-8497; f) D. Zhu, X. Yan, A. Ren, W. Cai, Z. Duan, Y. Luo, Anal. Methods 2019, 11, 2579-2584. 
WILEY-VCH

[14] F. Umland, E. Hohaus, K.Brodte, Chem. Ber. 1973, 106, 2427-2437.

[15] D. Frath, S. Azizi, G. Ulrich, P. Retailleau, R. Ziessel, Org. Lett. 2011, 13, 3414-3417.

[16] a) P. A. A. M. Vaz, J. Rocha, A. M. S. Silva, S. Guieu, New J. Chem. 2018, 42, 18166-18171; b) Y. Zhou, J. W. Kim, M. J. Kim, W.-J. Son, S. J. Han, H. N. Kim, S. Han, Y. Kim, C. Lee, S.-J. Kim, D. H. Kim, J.-J. Kim J. Yoon, Org. Lett. 2010, 12, 1272-1275; c) Z. Jiang, X. Wang, J. Ma, Z. Liu, Sci. China Chem. 2019, 62, 355-362.

[17] a) V. G. Jiménez, F. M. F. Santos, S. Castro-Fernández, J. M. Cuerva, P. M. P. Gois, U. Pischel, Araceli G. Campaña, J. Org. Chem. 2018, 83, 14057-14062; b) J. Li, X. Peng, C. Huang, Q. Qi, W.-Y. Lai, W. Huang Polym. Chem. 2018, 9, 5278-5285.

[18] a) A. Macé, N. Hellou, J. Hammoud, C. Martin, E. S. Gauthier, L. Favereau, T. Roisnel, E. Caytan, G. Nasser, N. Vanthuyne, J. A. G. Williams, F. Berrée, B. Carboni, J. Crassous, Helv. Chim. Acta 2019, 102, e1900044; b) N. Hellou, A. Macé, C. Martin, V. Dorcet, T. Roisnel, M. Jean, N. Vanthuyne, F. Berrée, B. Carboni, J. Crassous, J. Org. Chem. 2018, 83, 484-490.

[19] a) A. Terfort, H. Gorls, H. Brunner, Synthesis 1997, 1, 79-86; b) C. Shen, F. Gan, G. Zhang, Y. Ding, J. Wang, R. Wang, J. Crassous, H. Qiu, Mater. Chem. Front. 2020, 4, 837-844.
[20] X. Xie, Y. Yuan, R. Krüger, M. Bröring, Magn. Reson. Chem. 2009, 47, 1024-1030.

[21] a) K. Dhbaibi, L. Favereau, M. Srebro-Hooper, M. Jean, N. Vanthuyne, F. Zinna, B. Jamoussi, L. Di Bari, J. Autschbach, J. Crassous, Chem. Sci. 2018, 9, 735-742; b) K. Dhbaibi, L. Favereau, M. Srebro-Hooper, C. Quinton, N. Vanthuyne, L. Arrico, T. Roisnel, B. Jamoussi, C. Poriel, C. Cabanetos, J. Autschbach, J. Crassous, Chem. Sci. 2020, 11, 567-576.

[22] a) M. Srebro-Hooper, J. Autschbach, Annu. Rev. Phys. Chem. 2017, 68, 399-420; b) J. Autschbach, Chirality 2009, 21, E116-E152.

[23] a) O. E. Weigang Jr., J. A. Turner, P. A. Trouard, J. Chem. Phys. 1966 45, 1126-1134; b) Y. Liu, J. Cerezo, G. Mazzeo, N. Lin, X. Zhao, G. Longhi, S. Abbate, F. Santoro, J. Chem. Theory Comput. 2016, 12, 27992819; c) Q. Xu, Y. Liu, X. Zhao, S. Chen, Q. Li, M. Wang, C. Yang, Spectrochim. Acta A, 2020, 231, 118132; d) Y. Liu, Q. Xu, J. Sun, L. Wang, D. He, M. Wang, C. Yang, Spectrochim. Acta A, 2020, 239, 118475.

[24] C. Bannwarth, J. Seibert, S. Grimme, Chirality 2016, 28, 365-369.

[25] M. El Sayed Moussa, M. Srebro, E. Anger, N. Vanthuyne, C. Roussel, C. Lescop, J. Autschbach, J. Crassous, Chirality 2013, 25, 455-465.

[26] N. Zhao, C. Ma, W. Yang, W. Yin, J. Wei, N. Li, Chem. Commun. 2019, 55, 8494-8497. 


\section{Entry for the Table of Contents}

Insert graphic for Table of Contents here.

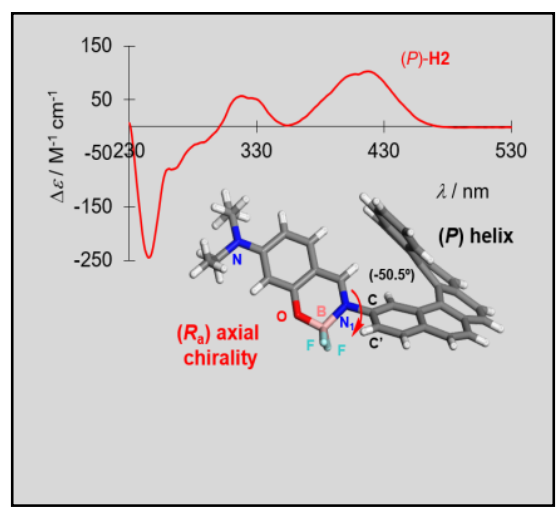

Helicene-mono- and bis-boranils have been prepared in enantiopure forms. The chiroptical (electronic circular dichroism and optical rotation) and photophysical properties (unpolarized and circularly polarized luminescence) of these new chiral emissive helicenes have been studied both experimentally and theoretically and highlight their combined helical and axial chirality effects.

Institute and/or researcher Twitter usernames: @JeanneCrassous 